\title{
Simulation of Active Suspension System for Half Vehicle Model under Different Road Profile
}

\author{
Dr. Farouk O. Hamdoon ${ }^{\dagger}$ and Dr. Batool M. Faisal ${ }^{\ddagger}$
}

${ }^{\dagger}$ Mechanical Engineering Department, College of Engineering, Wasit University, Wasit, Iraq.
${ }^{\star}$ Mechanical Engineering Department, College of Engineering, Wasit University, Wasit, Iraq.

\begin{abstract}
The main function of the vehicle suspension system is to provide comfort for passengers, road handling and vehicle stability. This paper proposes the application of PID controller (proportional, integral and derivative controller) for active suspension system of a half automobile model using MATLAB / SIMULINK. Time domain simulations are carried out to test the performance of the suspension system under different types of road profiles which are the primary inputs of the system. In this paper, three types of road profile inputs (bump, sine wave, random wave) are introduced to excite the suspension system. According to these road profile inputs, the performance response of passive and active suspension systems is simulated. Simulation results show that there is a significant improvement in the performance of the active system over the passive one.
\end{abstract}

Keywords: suspension system, half vehicle model, pid controller, simulink.

\section{Introduction}

A vehicle suspension system is a mechanism that isolates the vehicle's structure from the road irregularities. The basic function of the suspension system is to reduce the vibration transmitted to passengers in order to improve ride comfort and safety as the vehicle is passing over a bump or a hole.

A passive suspension system consists of springs and dampers which have fixed coefficients. There is no mechanism for feedback control to adjust these coefficients depending on the road conditions. In contrast, an active suspension system, which represents a closed loop control system, has the ability to respond to the road irregularities. Hence, the vibration transmitted to the vehicle is reduced.

Nowadays, different types of controller are utilized to control the active suspension system such as Fuzzy logic [1], H-infinity [2], LQR controller [3], PID controller [4] and Neural network [5].

The design and analysis of the suspension system is based on the mathematical modeling of the vehicle. A quarter vehicle model (one of the four wheels) is simple and widely used for dynamic analysis in many studies [69]. However, the disadvantage of the quarter model is its failure to capture the realistic dynamic response of the vehicle.

The aim of this paper is to propose the application of PID controller (proportional, integral and derivative controller) for active suspension system in a half vehicle model (one front and one rear wheel) using MATLAB / SIMULINK. Comparison between the performance of passive and active suspension systems are conducted under different road profiles inputs.

\section{Mathematical model}

In this work, a half model of vehicle with two degrees of freedom subjected to irregular road excitation is considered as shown in Figure (1). A half vehicle model is used to capture the bounce motion (upward and downward) and pitch motion (rotation about center of gravity) of the vehicle's body. The governing differential equations of motion can be directly derived by Lagrange's equations. The coordinates $x(t)$ and $\theta(t)$ are used as generalized coordinates to represent the bounce and pitch motions of the vehicle respectively [10].

$$
\begin{aligned}
& M \ddot{x}+\left(C_{1}+C_{2}\right) \dot{x}+\left(l_{2} C_{2}-l_{1} C 1\right) \theta+\left(K_{1}+K_{2}\right) x \\
& +\left(l_{2} K_{2}-l_{1} K_{1}\right) \theta=K_{1} y_{1}+K_{2} y_{2}+C_{1} \dot{y}_{1}+C_{2} \dot{y}_{2}
\end{aligned}
$$

$I \ddot{\theta}+\left(C_{2} l_{2}-C_{1} l_{1}\right) \dot{x}+\left(l_{2}^{2} C_{2}+l_{1}^{2} C_{1}\right) \dot{\theta}+\left(K_{2} l_{2}-K_{1} l_{1}\right) x$ $+\left(l_{1}^{2} K_{1}+l_{2}^{2} K_{2}\right) \theta=K_{2} l_{2} y_{2}-K_{1} l_{1} y_{1}+C_{2} l_{2} \dot{y}_{2}-$

$C_{1} l_{1} \dot{y}_{1}$ 
Where $M$ and I are mass and mass moment of inertia for the vehicle, respectively. $K$ represents the spring stiffness and $\mathrm{C}$ represents the damping coefficient, $l$ represents the distance from the center of mass to the front and rear wheels. Index 1 and index 2 refer to front and rear suspension system, respectively.

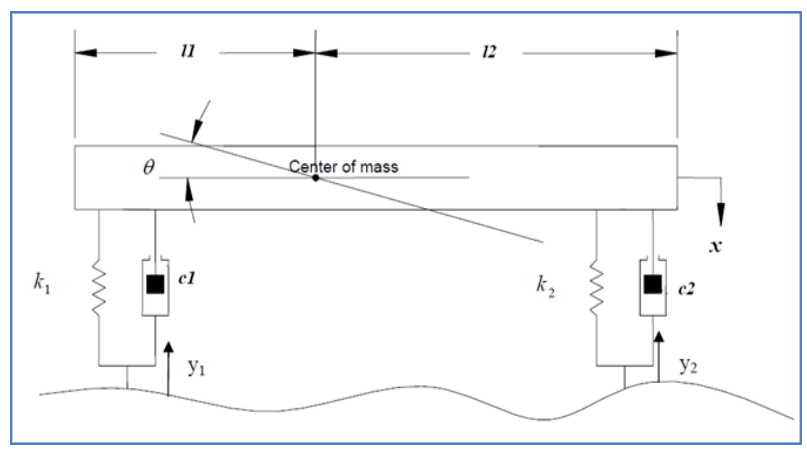

Fig 1: Half automobile model

Upon applying Laplace transform to the differential equations (1) and (2), the transfer functions $\mathrm{x}(\mathrm{s}) / \mathrm{y}_{1}(\mathrm{~s})$, $\theta(\mathrm{s}) / \mathrm{y}_{1}(\mathrm{~s}), \mathrm{x}(\mathrm{s}) / \mathrm{y}_{2}(\mathrm{~s}), \theta(\mathrm{s}) / \mathrm{y}_{2}(\mathrm{~s})$ of bounce and pitch motions due to each input $\mathrm{y}_{1}$ and $\mathrm{y}_{2}$ can be obtained. A MATLAB code has been written to provide these transfer functions. The input parameters for the model of half vehicle are presented in Table (1).

Table 1 Numerical parameters of half vehicle model [10]

\begin{tabular}{|c|c|c|}
\hline Descriptions & Symbols & Values \\
\hline Vehicles' mass & M & $2000 \mathrm{~kg}$ \\
\hline $\begin{array}{c}\text { Moment of inertia } \\
\text { about C.G }\end{array}$ & $\mathrm{I}$ & $\mathbf{2 5 0 0} \mathrm{kg} . \mathrm{m}^{2}$ \\
\hline $\begin{array}{c}\text { Front suspension } \\
\text { stiffness }\end{array}$ & $\boldsymbol{K}_{\boldsymbol{I}}$ & $\mathbf{3 0 0 0 0 \mathrm { N } / \mathrm { m }}$ \\
\hline $\begin{array}{c}\text { Rear suspension } \\
\text { stiffness }\end{array}$ & $\boldsymbol{K}_{2}$ & $\mathbf{3 0 0 0 0} \mathrm{N} / \mathrm{m}$ \\
\hline Front damping rate & $\boldsymbol{C}_{\boldsymbol{I}}$ & $\mathbf{3 0 0 0} \mathrm{N.s} / \mathrm{m}$ \\
\hline Rear damping rate & $\boldsymbol{C}_{2}$ & $\mathbf{3 0 0 0} \mathbf{~ N . s / m}$ \\
\hline $\begin{array}{c}\text { Front distance from } \\
\text { C.G }\end{array}$ & $\boldsymbol{l}_{\boldsymbol{I}}$ & $\mathbf{1 m}$ \\
\hline $\begin{array}{c}\text { Rear distance from } \\
\text { C.G }\end{array}$ & $\boldsymbol{l}_{2}$ & $\mathbf{1 . 5 m}$ \\
\hline
\end{tabular}

The half vehicle model with passive suspension system is implemented in SIMULINK as depicted in Figure (2).

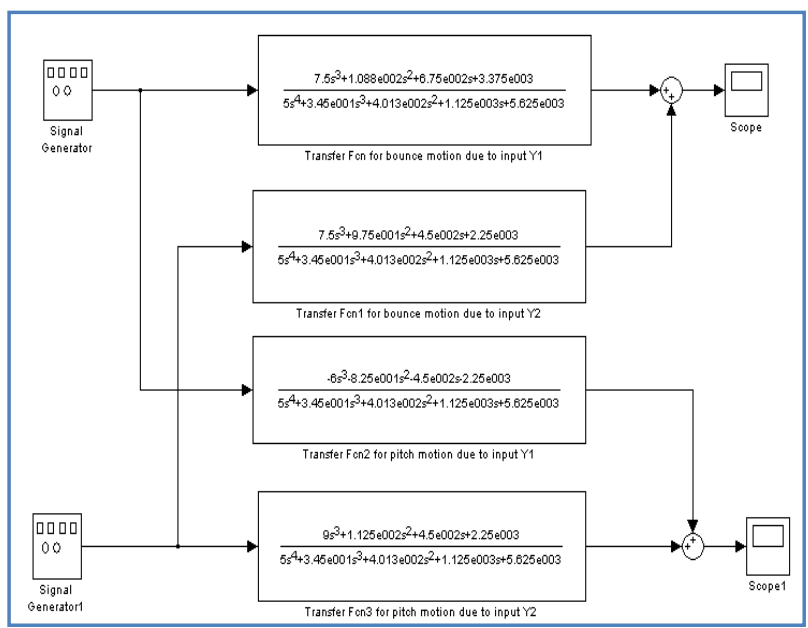

\section{PID controller}

A Proportional- Integral-Derivative (PID) controller is introduced for the active suspension system. PID controller is implemented into the active system to reduce the error between the actual and desired reference values. The transfer function of the PID controller is written as:

$C(s)=K_{P}+\frac{K_{I}}{s}+K_{D} S$

$K_{P,} \quad K_{I}$ and $K_{D}$ represent the proportional, integral and derivative gain parameters respectively. In this paper, PID controller is designed to guarantee that the output bounce and pitch displacements can be controlled and minimized as the disturbance occurs. Therefore, appropriate PID parameters must be chosen in order to ensure good performance for the system. There are several methods for tuning PID parameters [11]. In this study, the values of the three parameters of PID controller are tuned using heuristic (trial and error) method. The half vehicle model with an active suspension system using PID controller is implemented in SIMULINK as depicted in Figure (3). 


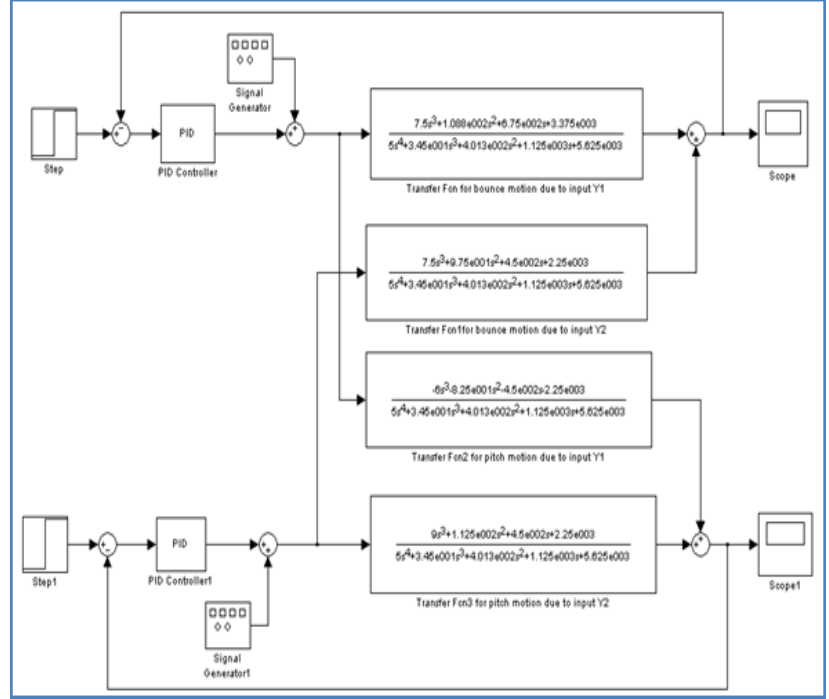

Fig 3: SIMULINK model of active suspension system with PID controller

\section{Road profile inputs}

Three different road profiles are presented in this study to excite the vehicle's suspension system. The first profile input is a single bump with $10 \mathrm{~cm}$ height. The second profile input is a sine wave with amplitude $10 \mathrm{~cm}$ and frequency $3 \mathrm{~Hz}$. The last profile input is a random road profile with maximum amplitude $10 \mathrm{~cm}$. These three road profile inputs are illustrated in Figure (4).
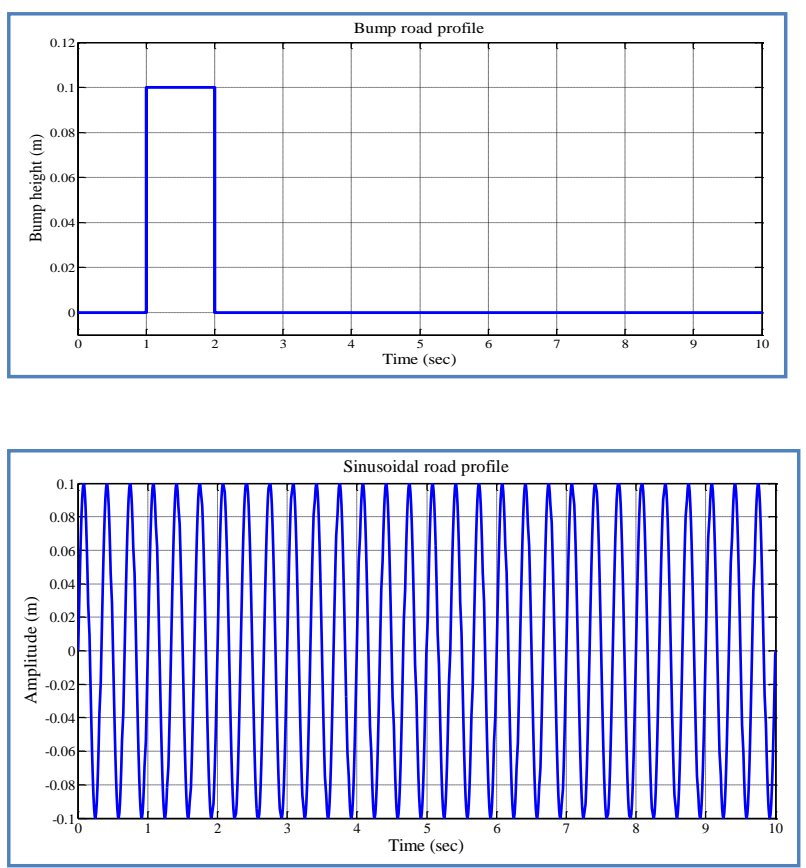

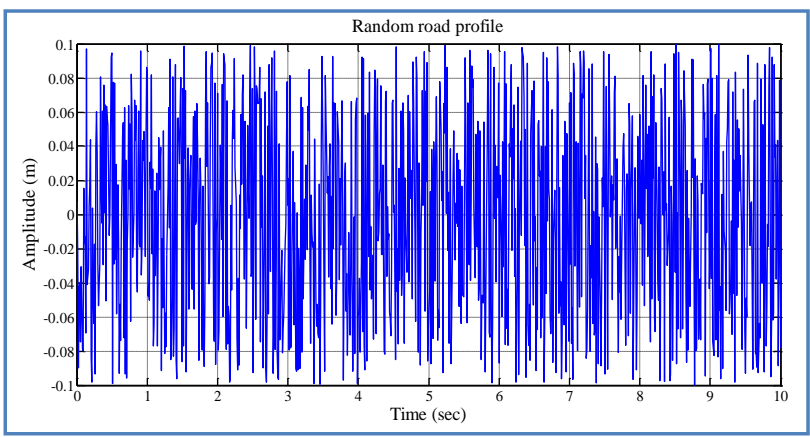

Fig 4: Road profile inputs

\section{Numerical results}

The present work is to study the dynamic behavior of a half vehicle model using MATLAB/SIMULINK. PID controller has been proposed for controlling an active suspension system of the modal of a half vehicle. Time domain simulation has been performed to test the dynamic response of the vehicle with passive and active suspension systems. The numerical simulation has been carried out under different types of road profiles.

Figures (5) \& (6) show the time response of bounce and pitch motions for bump road input. It can be clearly observed that with the passive suspension system the vehicle oscillates with large overshoot and high settling time. On the other hand, the active suspension system shows very small overshoot and very low settling time as compared with the passive one.

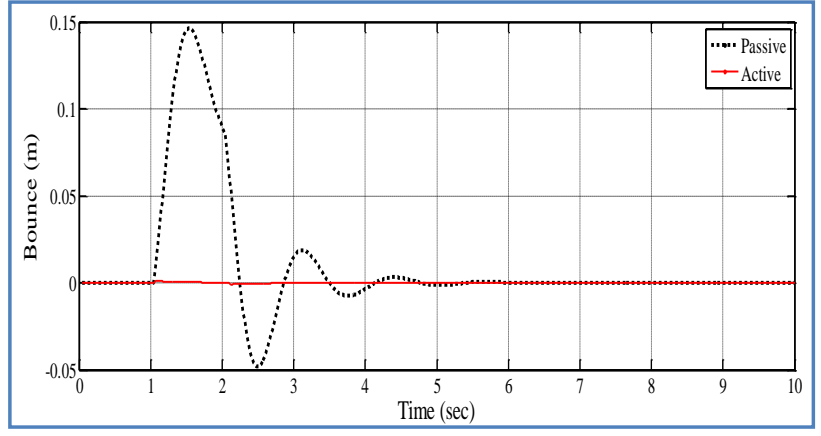

Fig 5: Bounce time response for bump road profile 


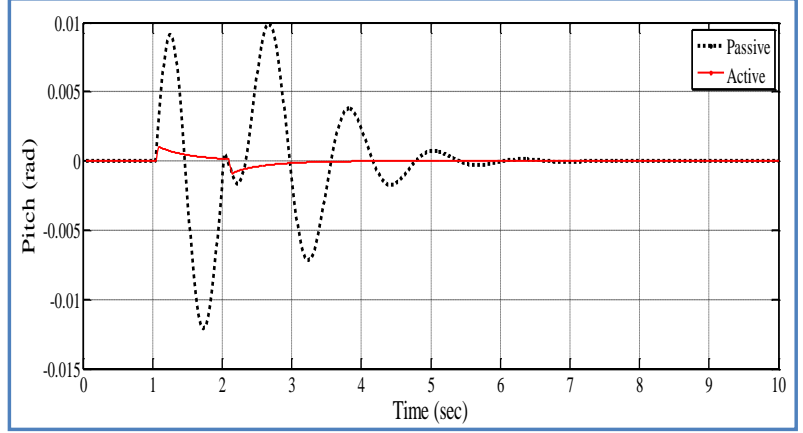

Figures (7) \& (8) show the time response of bounce and pitch motions for sinusoidal road input. It can be noted that the active suspension system reduces the maximum bounce and maximum pitch by $94.4 \%$ \& $85.2 \%$ respectively. Also, the results show that the active suspension system achieves very good performance in steady state response.

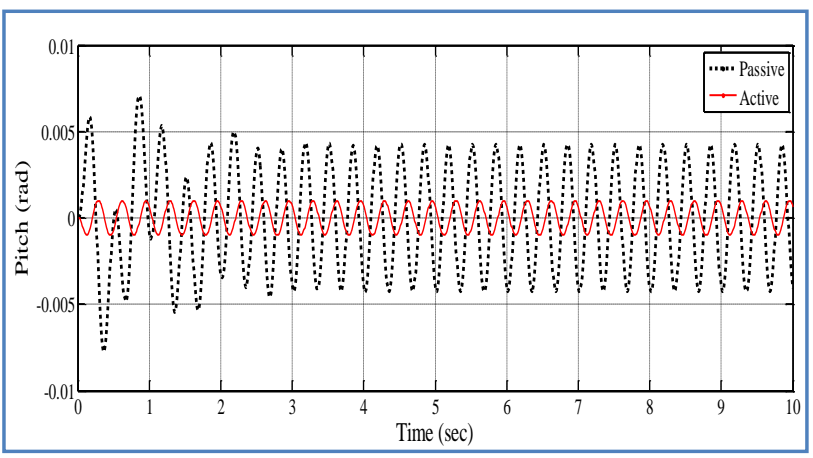

Fig 7: Bounce time response for sinusoidal road

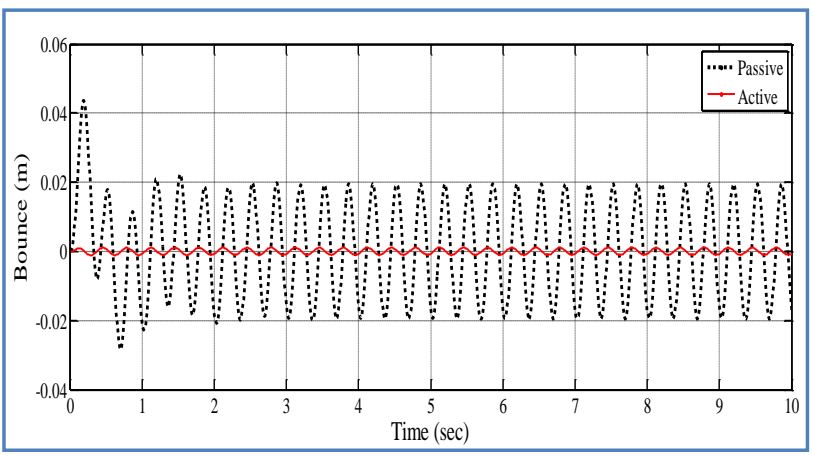

Fig 8: Pitch time response for sinusoidal road Figures (9) \& (10) show the time response of bounce and pitch motions for random road input. The results illustrate that in the case of active suspension system, a significant improvement on the dynamic performance is achieved.

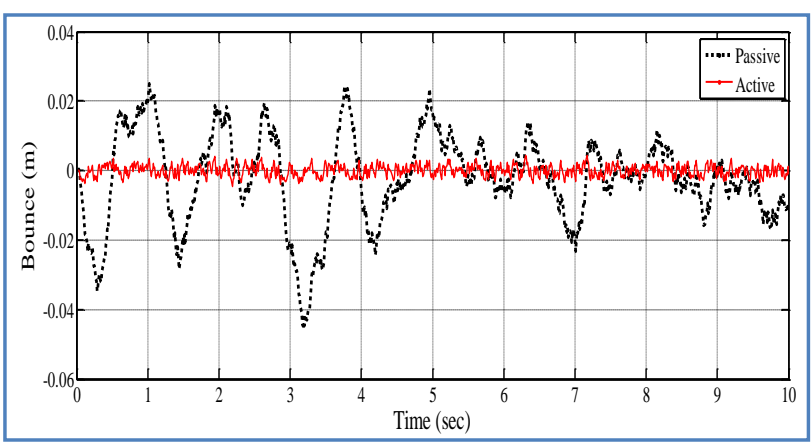

Fig 9: Bounce time response for random road profile

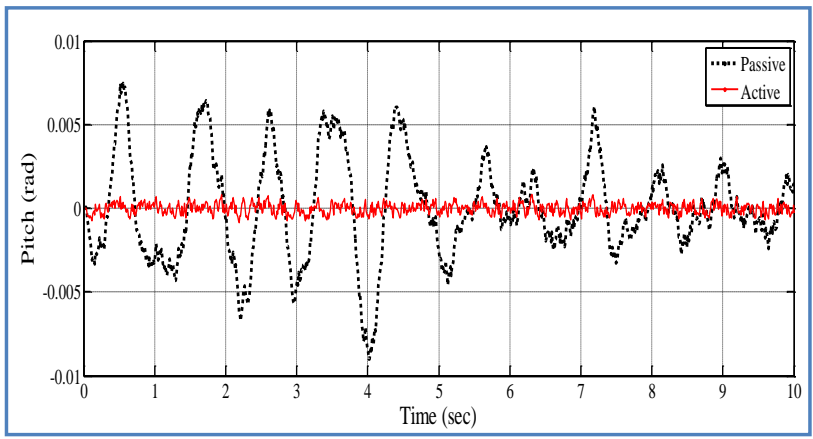

Fig 10: Pitch time response for random road

From the results obtained it is noticed that the maximum bounce and pitch for bump road input are larger than that for sinusoidal and random inputs. It can also be seen that in the steady state response the maximum bounce and pitch for random road input are larger as compared with sinusoidal road input.

\section{Conclusions}

In this paper, PID controller has been designed and used for controlling the active suspension system of the modal of a half vehicle. The dynamic behavior of the vehicle's model is investigated under different road profile inputs. The results proved that the implementation of PID controller in an active suspension system is efficient in controlling the vehicle's vibrations for all road profiles considered. This results in great comfort and better stability of the vehicle. A future work is to apply the active suspension system for a full vehicle model and test the performance using real practical system. 


\section{References}

[1] Wu S. J., Chiang H. H., Chen J. H. and Lee T. T., "Optimal fuzzy control design for half-car active suspension systems" IEEE Proceeding of the International Conference on Networking, Sensing and Control. March. Taipei, Taiwan: IEEE. 2004.

[2] Shariati A., Taghirad H. D. and Fatehi A., "Decentralized robust $\mathrm{H}-\infty$ controller design for a full car active suspension system" Control 2004. University of Bath, United Kingdom. 2004.

[3] Rosheila Binti Darus, "Modeling and control of active suspension for a full car model" M.Sc. Thesis, University Teknologi Malaysia, 2008.

[4] M. S. Kumar, "Development of Active Suspension System for Automobiles using PID Controller" Proceedings of the World Congress on Engineering, London, U.K., Vol.2, 2008.

[5] Ikbal Eski and Sahin Y1ldırım, "Vibration control of vehicle active suspension system using a new robust neural network control system" Simulation Modelling Practice and Theory, 2009, Vol.17, pp.778-793.

[6] Abdolvahab Agharkakli, Chavan U.S. and Phvithran S., "Simulation and analysis of passive and active suspension system using quarter car model for nonuniform road profile" International Journal of Engineering Research and Applications (IJERA), 2012,Vol.2 , No.5 , pp.900-906.

[7] Swati Gaur and Sheilza Jain, "Vibration control of bus suspension system using PI and PID controller" International Journal of Advances in Engineering Sciences , 2013, Vol.3 , No.3, pp.94-99.

[8] Muhammad Ibrahim, Amir Bature, Suleeiman Babani and Najib Dankadai, "Conventional and Intelligent controller for quarter car suspension system" International Journal of Technical Research and Applications (IJTRA), 2014, Vol.2, No.1, pp.24-27.

[9] Narinder Singh , Himanshu Chhabra and Karansher Bhangal, "Robust Control of Vehicle Active Suspension System" International Journal of Control and Automation (IJCA), 2016, Vol. 9, No.4, pp. 149-160.

[10] Alireza Mohammadzadeh and Salim Haider, "Analysis and design of vehicle suspension system using MATLAB and SIMULINK" Grand Valley State University, 2006.

[11] Li Y., Ang K. H. and Chong G. C. Y., "PID control system analysis and design" IEEE Control Systems Magazine, 2006,Vol. 26, No.1, pp. 32-41. 